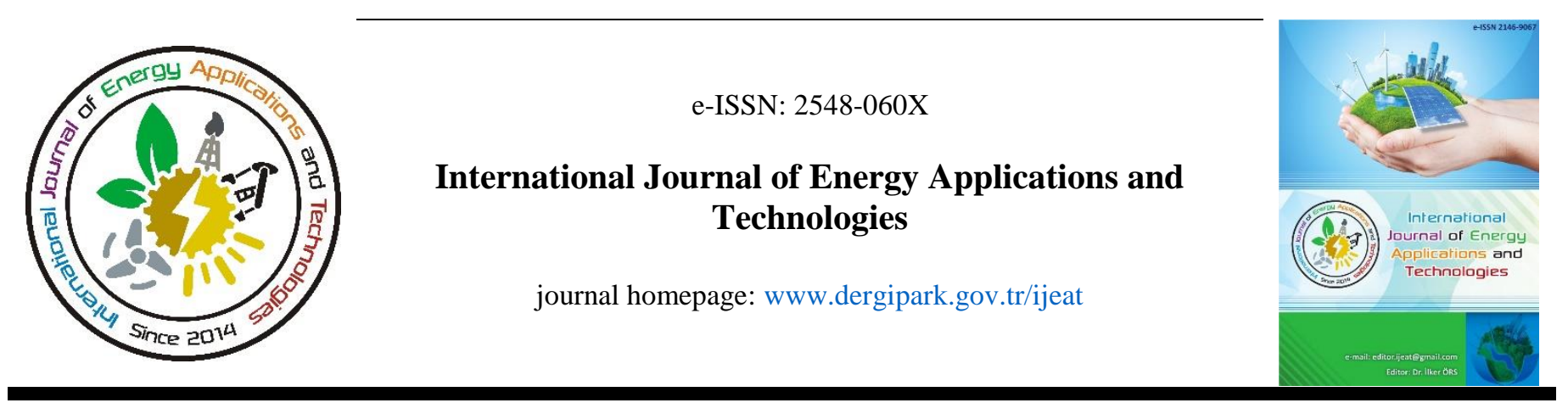

Original Research Article

\title{
Analysis of electronic circuit transformer with experimental and finite elements
}

\author{
Yıldırım Özüpak ${ }^{1 *}$, İbrahim Halil Teke ${ }^{2}$, Mehmet Salih Mamiş ${ }^{3}$ \\ ${ }^{I}$ Program of Electrical and Energy, Silvan Vocational School, Dicle University, Diyarbakur, Turkey \\ ${ }^{2} A f$ şin Elbistan B Thermal Power Plant, Ë̈AŞ, Kahramanmaraş, Turkey \\ ${ }^{3}$ İn̈̈n̈̈ University, Engineering Faculty, Electrical and Electronic Engineering Department, Malatya, Turkey
}

\section{ARTICLE INFO \\ * Corresponding author yildirimozupak@gmail.com \\ Received January 27, 2021 \\ Accepted March 22, 2021 \\ Published by Editorial Board Members of IJEAT \\ (C) This article is distributed by Turk Journal Park System under the CC 4.0 terms and conditions.}

doi: 10.31593/ijeat.869359

\begin{abstract}
Transformers, one of the most important elements of energy transmission and distribution systems, can be produced as a result of high cost and long-term studies. It is necessary to know the mechanical, electrical and magnetic properties of a transformer in the manufacturing process. Modeling of the transformers to be designed with a reliable simulation program in order to operate at targeted values and efficiency is important in terms of ensuring test criteria and minimizing the problems that may arise later. Thanks to advanced computer techniques, it is possible to identify design errors and correct them through a simulation program.

In this paper, ANSYS Maxwell 3D software based on Finite Element Method (FEM) and widely used in transformer simulation was used. With this program, it is aimed to investigate the magnetic field density, magnetic field intensity, magnetic flux lines, current density values in the coil and core of the transformer and the effects of these values on transformer losses. Considering the nominal values of the single phase $90 \mathrm{VA}$ transformer, its electrical and physical values were measured by experimental studies in the laboratory environment, and the necessary parameters and values were calculated based on these measurements. The theoretically calculated values are compared with the experimental study results and the values calculated with ANSYS Maxwell program. It was observed that the experimental study results and the results of the model created in the program confirmed each other.
\end{abstract}

Keywords: Transformer; FEM; Magnetic flux; Maxwell-3D

\section{Introduction}

Transformers are static devices that are used in AC systems to transfer the level of voltage at a fixed frequency through magnetic induction and have no moving parts. Transformers are electrical machines that enable the electrical power generated at low voltage values to be transmitted at higher voltage levels over long distances and to be used at lower voltage levels.

In recent year, computer simulations are used for pre-design analysis of transformers. Among these, ANSYS Maxwell is the most widely used packaged software and there are many studies on the applications of this software. ANSYS Maxwell is a software developed for low frequency electromagnetic field simulation. ANSYS uses Maxwell Finite Element Method for magnetic and electrical analysis. Thus, it provides a fast and reliable analysis before the applications in practical studies.

Using magneto-static analysis in ANSYS Maxwell simulation platform, the design and modeling of a threephase core-type transformer including coil and connection points is described in detail [1]. With the finite element method of ANSYS Maxwell, core losses in 2-dimensional and 3-dimensional state of the transformer with $30 \mathrm{MVA}$ power were calculated separately for $50 \mathrm{~Hz}$ and $60 \mathrm{~Hz}$ and the results were compared [2]. As a result of these 
comparisons, it has been shown that the core loss value for $60 \mathrm{~Hz}$ frequency value is higher than the core loss value at 50 $\mathrm{Hz}$ frequency in 2-dimensional and 3-dimensional situations. Based on the 2-dimensional version of a single-phase shelltype transformer with a power of 10 MVA with the ANSYS Maxwell program, the forces occurring in its windings due to inrush current and short circuit current were investigated [3]. With this study, it has been seen that the value of the highest amplitude of the inrush current that can occur in the transformer windings is equal to the nominal value of the short circuit current. However, it has been emphasized that inrush current and short circuit current can cause serious damage to transformer windings. In addition, it has been determined that the axial forces caused by the inrush current are greater than the axial forces caused by the short circuit current.

With the magnetic circuit theory and finite element method, a 3-phase, dry type distribution transformer design with 100 $\mathrm{kVA}$ power, 11/0.4 $\mathrm{kV}$ voltage values and delta / star connection structure has been studied [4]. While designing the transformer, it was argued that it would not be completely correct to use the circuit theory model for parameters such as winding impedance, leakage inductance, hot spot temperature, etc. [5, 9-12].

Using ANSYS Maxwell software, a real transformer model with 3 inputs and 5 outputs has been studied. Before applying the software modeling, studies have been done on a real transformer [6]. The accuracy of different models of numerical methods has been investigated in order to calculate transformer's no-load losses. Unloaded losses are calculated using analytical method and Finite Element Analysis software [7, 13-16]. In their article study using the Ansoft Maxwell analysis program, the flux density and core losses were analyzed for the transformer using 7 different $\mathrm{T}$ connection forms (same core material. it was observed that the least is the $15^{\circ}-90^{\circ}-75^{\circ}$ model [8].

In this paper, it is aimed to compare the results obtained by using ANSYS Maxwell 3D software with theoretical calculations and experimental study results.

\section{Material and Methods}

Losses occurring in transformer have to be taken into account in real models of transformers. Core losses (hysteresis losses and eddy current losses), copper losses and leakage fluxes should be taken into account in creating such a model. When these criteria are taken into consideration, various measurements and tests are performed to find the equivalent electrical model parameters of the transformer.

\subsection{Transformer losses}

In transformers, when the input winding is supplied by the voltage source (network, busbar, generator, etc.), the open output winding ends is expressed as idle operation. Idle running current decreases of nominal current in large power transformers. Since the idle current is very small, copper loss in the input windings is negligible. When this loss is neglected, if the input windings are fed while no load is connected to the output winding flies, the resulting losses will only cause the core loss. The instantaneous value of the magnetic flux, the instantaneous value of the voltage induced at the input winding ends, the angular frequency, the average value of the induced voltage and the maximum value of the magnetic flux are given by equations (1) - (5), respectively.

$$
\begin{aligned}
& \Psi=\Phi_{\text {max }} \sin (\omega t) \\
& e_{1}=\frac{d \lambda_{1}}{d t}=N_{1} \frac{d \Psi}{d t}=\omega N_{1} \Phi_{\max } \cos (\omega t) \\
& \omega=2 \pi f \\
& E_{1}=\frac{2 \pi f}{\sqrt{2}} N_{1} \Phi_{\text {max }}=\sqrt{2} \pi f N_{1} \Phi_{\text {max }} \\
& \Phi_{\text {max }}=\frac{E_{1}}{\sqrt{2} \pi f N_{1}}
\end{aligned}
$$

The following equations are used to express the value of magnetic flux in terms of density and surface area.

$$
\begin{aligned}
& \Psi=\int_{0}^{S} B \cdot d_{A}=B \cdot S=B_{\max } \cdot S \cdot \sin (\omega t) \\
& R_{H}=\rho \frac{l_{H}}{A_{H}}=0.0175 \frac{\Omega m m^{2}}{m} \frac{752(0.2 m)}{\pi(0.2 m m)^{2}} \cong 20.95 \Omega \\
& R_{L}=\rho \frac{l_{L}}{A_{L}}=0.0175 \frac{\Omega m m^{2}}{m} \frac{164(0.2 m)}{\pi(0.4 m m)^{2}} \cong 1.14 \Omega \\
& B_{\max }=\frac{E_{1}}{\sqrt{2} \pi f S N_{1}}=\frac{E_{1}}{4.44 S f N_{1}}
\end{aligned}
$$

Where $\mathrm{S}$ is surface area, $\mathrm{B}$ is magnetic flux density, $\mathrm{R}$ is resistance, $\mathrm{E}$ is voltage, $\mathrm{N}$ is turn number, $\rho$ is self resistance.

\subsection{No-load test of transformer}

If the core of the transformer is exposed to a time-varying magnetic flux, core loss occurs in a magnetic material. In general, the loss in the core is divided into two components: $\mathrm{Pc}$, hysteresis loss $\mathrm{Ph}$ and eddy current loss Pe. According to the Steinmetz equation, measurement and calculation of core losses are normally done with sinusoidal flux density of varying magnitude and frequency. These measurements and calculations are based on standard coil and often consist of two terms [18]. 


$$
\begin{aligned}
& P_{C}=P_{h}+P_{e} \\
& P_{C}=k_{h} f B^{n}+k_{e} f^{2} B^{2}
\end{aligned}
$$

Where $f$ is the frequency of the magnetic circuit expressed in the above equations, $\mathrm{B}$ magnetic flux density, $\mathrm{k}_{\mathrm{h}}$ and $\mathrm{k}_{\mathrm{e}}$; hysteresis and eddy current coefficients, $\mathrm{n}$ is the Steinmetz coefficient. These coefficients are coefficients that depend on the lamination material, thickness, conductivity, frequency and other factors. In general, the calculation of core losses can be calculated by taking into account the excess losses factor, as indicated by the equation below.

$$
P_{C}=P_{h}+P_{e}+P_{e x}=k_{h} f B^{n}+k_{e} f^{2} B^{2}+k_{a} f^{1.5} B^{1.5}
$$

\subsection{Full load test}

In the laboratory environment, if the transformer is loaded at nominal value, the real properties and especially the efficiency of the transformer can be calculated by measuring voltage, current and power. In order to realize these operations, the resistance value of the variable load connected to the secondary is changed by applying the nominal input voltage to the primary side of the transformer until the nominal output current is obtained. The purpose of the full load test is to obtain the load losses. Copper losses from full load test are obtained by the equation given below.

$$
P_{C u}=I^{2} R
$$

Copper loss can be reduced by reducing the value of the winding resistance while the transformer is in the design process.

\subsection{Finite Element Method}

Finite Element Method (FEM) is a numerical technique used to find approximate solutions of partial differential equations as well as integral equations. Finite Elements Method is effectively used as a numerical method in solving complex engineering problems precisely. The basic logic of the finite element method is to divide the structure into a finite number of elements, these elements are usually connected by means of nodes (mesh) and obtain an approximate solution. Finite element method, which provides the solution of complex engineering problems with controllable parts by simplifying them, is a common and useful solution method used in many engineering applications.

\subsection{Modeling of transformer}

ANSYS@ Maxwell program, which realizes a solution based on Transformer Finite Elements method, is modeled as 3-D of the environment. The values of the modeled transformer are presented in Table 1.
Table 1. Characteristics of the transformer

\begin{tabular}{|l|l|}
\hline Power (VA) & 90 \\
\hline Input voltage (V) & 220 \\
\hline Output voltage (V) & 48 \\
\hline Primer turn number $(\mathrm{N})$ & 752 \\
\hline Seconder turn number $(\mathrm{N})$ & 164 \\
\hline Input current $(\mathrm{A})$ & 0.409 \\
\hline Output current $(\mathrm{A})$ & 1.875 \\
\hline Frequency $(\mathrm{Hz})$ & 50 \\
\hline Load loss $(\mathrm{W})$ & 9 \\
\hline Core loss $(\mathrm{W})$ & 4 \\
\hline Volume of core $\left(\mathrm{m}^{3}\right)$ & $0.222 * 10^{-3}$ \\
\hline Core material & $\mathrm{M} 125-027 \mathrm{~S}$ \\
\hline Conductivity & $5000000 \mathrm{~S} / \mathrm{m}$ \\
\hline $\mathrm{K}_{\mathrm{h}}$ & 65.48 \\
\hline $\mathrm{K}_{\mathrm{c}}$ & 0.59 \\
\hline
\end{tabular}

Mesh structure in 3D structure of single phase transformer is shown in Figure 1. The $50 \mathrm{~Hz}$ frequency B-H curve of M125$027 \mathrm{~S}$ material used as core material in the transformer is as shown in Figure 2.

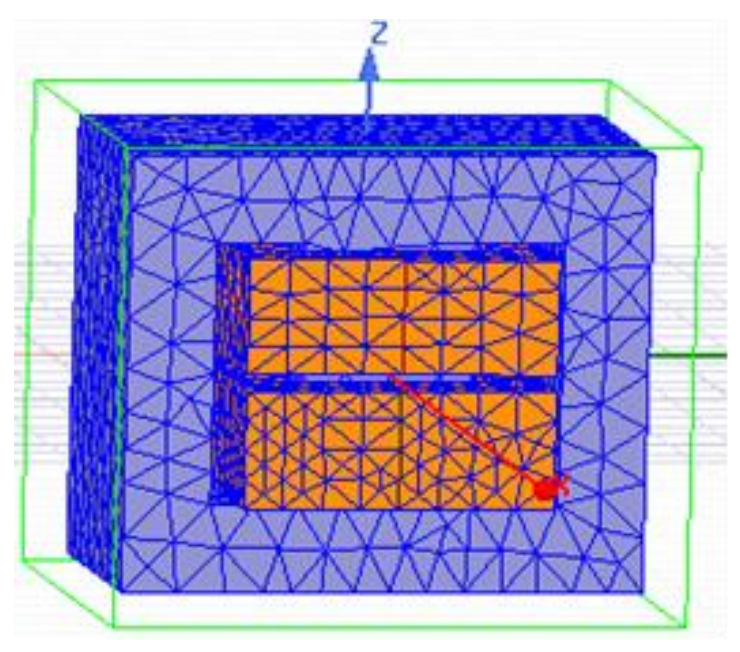

Fig. 1. Modeling mesh

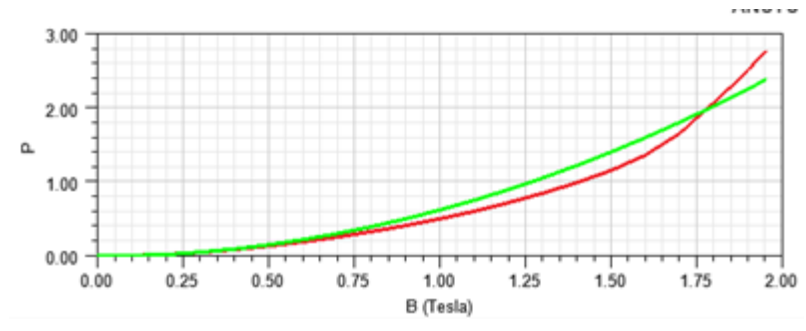

Fig. 2. Core material B-H curve

\subsection{Experimental tests}

In this study, experimental tests of the transformer were performed in the laboratory to verify the results and the results were obtained. The results obtained were compared with the results obtained with FEM. Core and copper loss values obtained from laboratory experiments are presented in Figure 3 and Figure 4. 


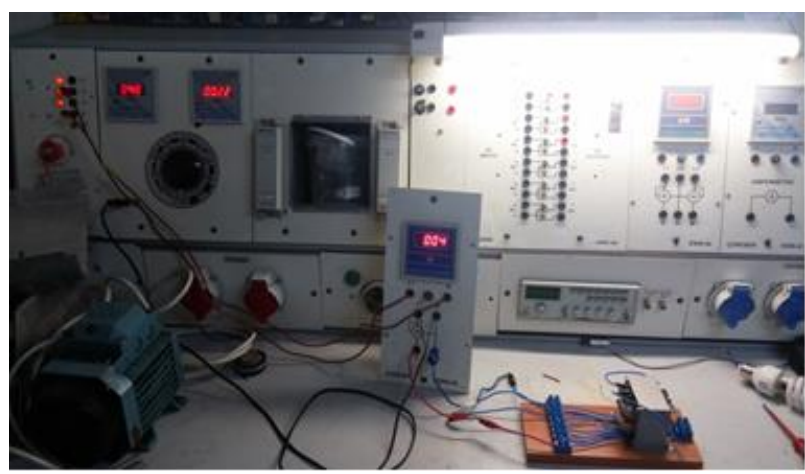

Fig. 3. Core loss

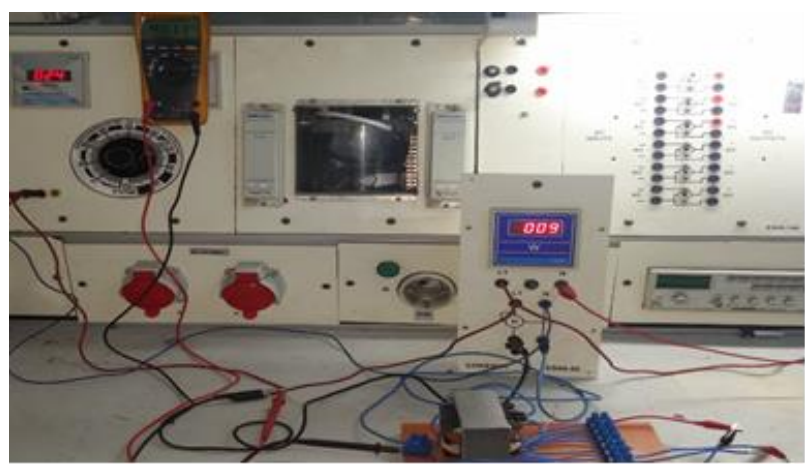

Fig. 4. Copper loss

\section{Results and Discussion}

In this section, the comparison and consistency of the results obtained by FEM simulations and experimentally obtained are given. Magnetic field distribution, core losses and copper losses of transformers were obtained by both methods. In addition, magnetic field strength and current density on the transformer are presented.

\subsection{FEM simulation results}

As in the short circuit test of the 3D transformer, this test also performs analysis for the predefined time interval and time step in the simulation based on transient analysis. In this simulation test, copper losses for $50 \mathrm{~Hz}$ frequency were obtained from the simulation of the transformer $3 \mathrm{D}$ model. The copper loss curve is given in Figure 5.

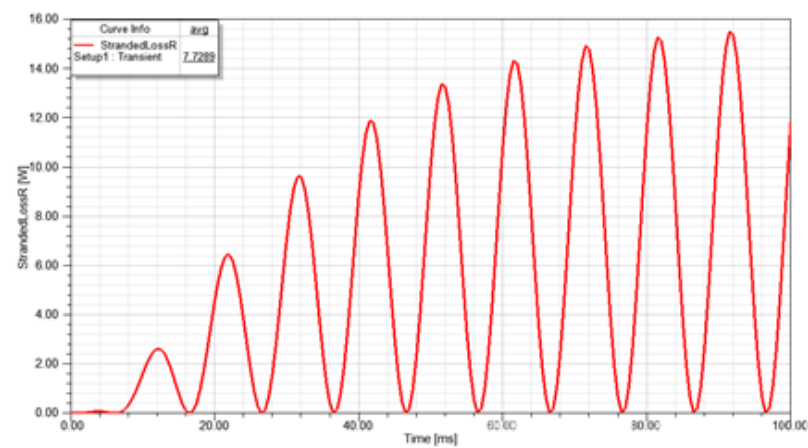

Fig. 5. Copper losses at full load

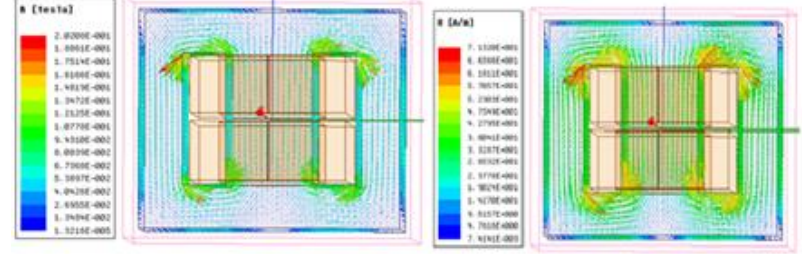

Fig. 6. Magnetic flux and magnetic field intensive

Core losses and magnetic field strength were obtained from the idle test of the transformer. The values obtained are given in Figure 7 and Figure 8.

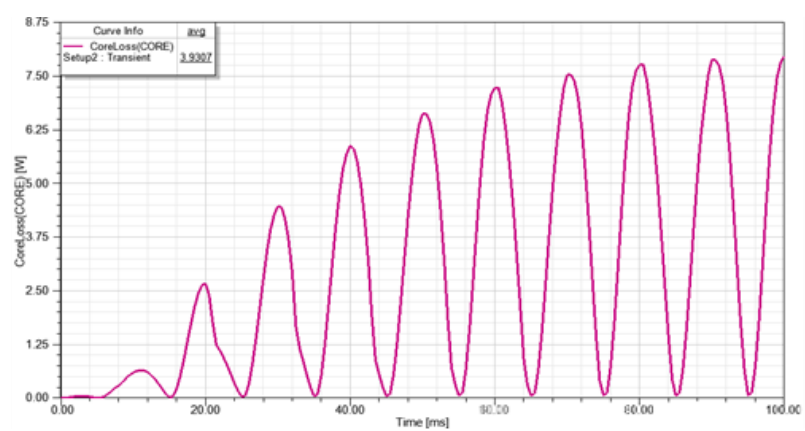

Fig. 7. Core loss

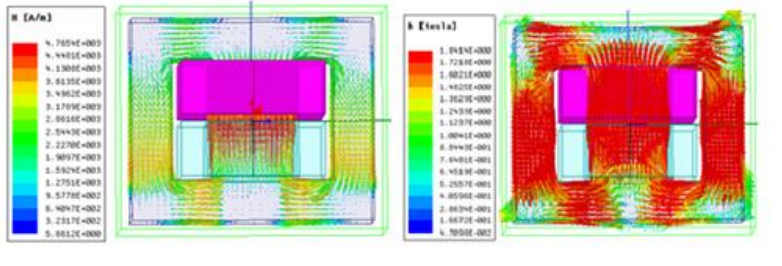

Fig. 8. Magnetic field values obtained from transformer idle test

\subsection{Experimental results}

In the experimental results, the core loss was $4.1 \mathrm{~W}$, copper loss, $9 \mathrm{~W}$. The magnetic flux obtained in the open circuit test was $1.88 \mathrm{~T}$, the magnetic field value obtained from the full load test was 2.7 T. Experimental results and results obtained from FEM simulation were close to each other. This situation reveals the accuracy and usability of the method used. The values obtained are compared in Table 2.

Table 2. Comparison of experimental, theoretical and FEM results.

\begin{tabular}{cccc}
\hline Parameter & Experimental & FEM & Theoretical \\
\hline $\begin{array}{c}\text { Core loss } \\
(\mathbf{W})\end{array}$ & 4 & 3.93 & 3.95 \\
$\begin{array}{c}\text { Copper loss } \\
(\mathbf{W})\end{array}$ & 8.93 & 8.82 & 7.754 \\
$\begin{array}{c}\text { Magnetic flux } \\
(\mathbf{T})\end{array}$ & 1.89 & 1.86 & 1.81 \\
$\begin{array}{c}\text { Inductance } \\
(\mathbf{m H})\end{array}$ & 34 & 33.6 & 33 \\
$\begin{array}{c}\text { Resistance } \\
(\mathbf{\Omega})\end{array}$ & 1.66 & 1.52 & 1.4 \\
\hline
\end{tabular}


It is aimed to compare the results obtained by using ANSYS Maxwell 3D software with theoretical calculations and experimental study results. B-H and B-P values were created as a result of determining the thickness and operating frequency of the laminated sheets used in the transformer core on the program. By defining the ANSYS Maxwell model, the total core losses and copper losses were determined according to the field density value obtained after the 3D magnetic field analysis, and the change over time was graphically obtained in the transient analysis. In the ANSYS environment, the electromagnetic field distribution formed in the windings and core of power transformers was analyzed by $3 \mathrm{D}$ modeling. Thus, the designs of the transformer's core and windings were realized and the performance of the transformer could be monitored before the design with 3D modeling. In this study, evaluations have been made on the basis of experimentally obtained measurements and simulation results. In this way, some inferences about the core, winding and power values to be used in a new transformer to be designed can be made.

\section{Conclusion}

In this study, simulation models of transformers based on FEM are presented. Theoretical calculations, experimental measurements and analysis processes were carried out with ANSYS Maxwell program for single phase transformer. With the given and obtained circuit elements of the singlephase transformer, the sample transformer was designed in ANSYS Maxwell program, but due to the physical conditions of the cores and windings used in the real transformer, it was observed that the values obtained as a result of simulation in the ANSYS Maxwell program were slightly different from the measurements made in the laboratory-workshop environment. The core loss was found as $3.9307 \mathrm{~W}$ in the open circuit test performed with the $3 \mathrm{D}$ model, and the copper loss was found as $7.7289 \mathrm{~W}$ in the short circuit test. However, in the measurements made in the laboratoryworkshop environment, the core loss was measured as $4 \mathrm{~W}$ and the copper loss as $9 \mathrm{~W}$. Therefore, the results obtained confirm the designed product.

\section{Acknowledgment}

This study was carried out with ANSYS Electronic 19.0, a commercial program. This study was supported by Inönü University BAP project no 639. Thank you for your contribution.

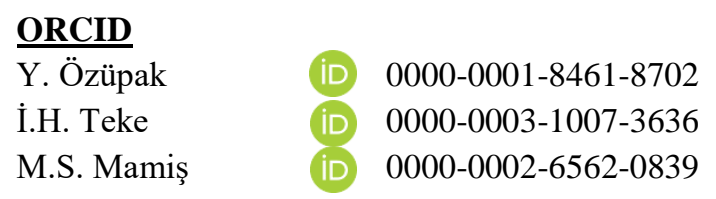

\section{References}

[1] Rao, Y., Structural Modeling of A Three Phase Core Type Transformer Using ANSYS Maxwell 3D, 2016. International Journal of Innovative Research In Electrical, Electronics, Instrumentation And Control Engineerıng, 4:4, 17-20.

[2] Sharifian, M.B.B., Esmaeilzadeh, R., Farrokhifar, 2008. Computation of a single-phase shell-type transformer windings forces caused by inrush and short-circuit currents, Journal of Computer Science, 4:1, 51-58.

[3] Orosz, T., Kleizer, G., Iváncsy T., Tamus, Z. Á. 2016. Comparison of methods for calculation of core-form power transformer's core temperature rise, Periodica Polytechnica Electrical Engineering and Computer Science, 60:2, 88-95

[4] Chitaliya, G. H., Joshi, S. K., 2013. Finite element method for designing and analysis of the transformer a retrospective, Proc. of Int. Conf. on Recent Trends in Power, Control and Instrumentation Engineering, 5458.

[5] Yusoff, N. A. M., Karim, K. A., Ghani, S. A., Sutikno, Jidin, T. A., 2015. Multiphase transformer modelling using finite element method, International Journal of Power Electronics and Drive System (IJPEDS), 6:1, 5664.

[6] Dawood, K., Cinar, M. A., Alboyacı, B., Sonmez, O. 2017. Efficient finite element models for calculation of the no-load losses of the transformer, International Journal of Engineering \& Applied Sciences (IJEAS), 9:3, 11-21.

[7] M. Lee, H. A. Abdullah, J. C. Jofriet, D. Patel, 2010. Thermal modeling of disc-type winding for ventilated dry-type transformers. Electric Power Systems Research, 80, 121-129.

[8] Soh T. L. G, Said D. M, Ahmad N, Nor K. M, Salim F 2013. Experimental study on the impact of harmonics on transformer. IEEE 7th International Power Engineering and Optimization Conference (PEOCO), 686-690.

[9] Nageswara Rao, M., Malay Mandal 2011. Impact of Harmonics, Estimation of Losses and Life expectanc \& Mitigation of ill effects. https://www.academia.edu/6676494/Distribution_Tran sformer_Impact_of_Harmonics_IEEE_Format_2. Erişim tarihi (10.10.2017)

[10] Sadati, S.B., Tahani, A., Jafari, M., Dargahi, M., 2008. Derating of Transformers under Non-sinusoidal Loads. in: 11th International Conferenec on Optimization of Electrical and Electronic Equipment, OPTIM, 263-268.

[11] Teke, I. H., Özüpak, Y. and Mamiş, M. S. 2019. Electromagnetic Field and Total Loss Analysis of 
Transformers by Finite Element Method. International Journal of Engineering and Computer Science. 8(01), 24451-24460.

[12] IEEE, 2006-2007. Standard for standard general requirements for liquid-immersed distribution, power, and regulating transformers. IEEE Std C57.12.00

[13] Ryder, S. A., Vaughan, I. J. 2004. A simple method for calculating core temperature rise in power transformers. IEEE Transactions on Power Delivery. 19(2), 637-642.

[14] Del Vecchio, R. M., Poulin, B., Feghali, P. T., Shah, D. M., Ahuja, R. 2001. Transformer design principles with applications to core-form power transformers. CRC Press.

[15] Tenyenhuis, E. G., Girgis, R. S., Mechler, G. F., Zhou, $\mathrm{G}$, 2002. Calculation core hot-spot temperature in power and distribution transformers. IEEE Transactions on Power Delivery. 17(4), 991-995.

[16] Özüpak Y, Mamis M. S 2019. Realization of electromagnetic flux and thermal analyses of transformers by finite element method. IEEJ Transactions on Electrical and Electronic Engineering, 14(10), 1478-1484.

[17] K.T. Muthanna, A. Sarkar, K. Das, K. Waldner 2006. Transformer Insulation Life Assessment. IEEE Trans, Power Deliv. 21150 - 156.

[18] ANSYS User guide 2020. 